\title{
LA CARRERAS DE MEDICINA VETERINARIA Y ZOOTECNIA DE LA FACULTAD DE MEDICINA VETERINARIA EN LA UNIVERSIDAD AGRARIA DE LA HABANA (UNAH) LOGRA LA CONDICIÓN DE EXCELENCIA
}

\section{THE CAREERS OF VETERINARY MEDICINE AND ANIMAL HUSBANDRY OF THE FACULTY OF VETERINARY MEDICINE IN THE AGRARIAN UNIVERSITY OF HAVANA (UNAH) REACH THE STATUS OF EXCELLENCE}

\author{
Del Pozo Pedro Pablo
}

Decano de la Facultad Medicina veterinaria, Universidad Agraria de la Habana, Cuba, e-mail: delpozo@isch.edu.cu

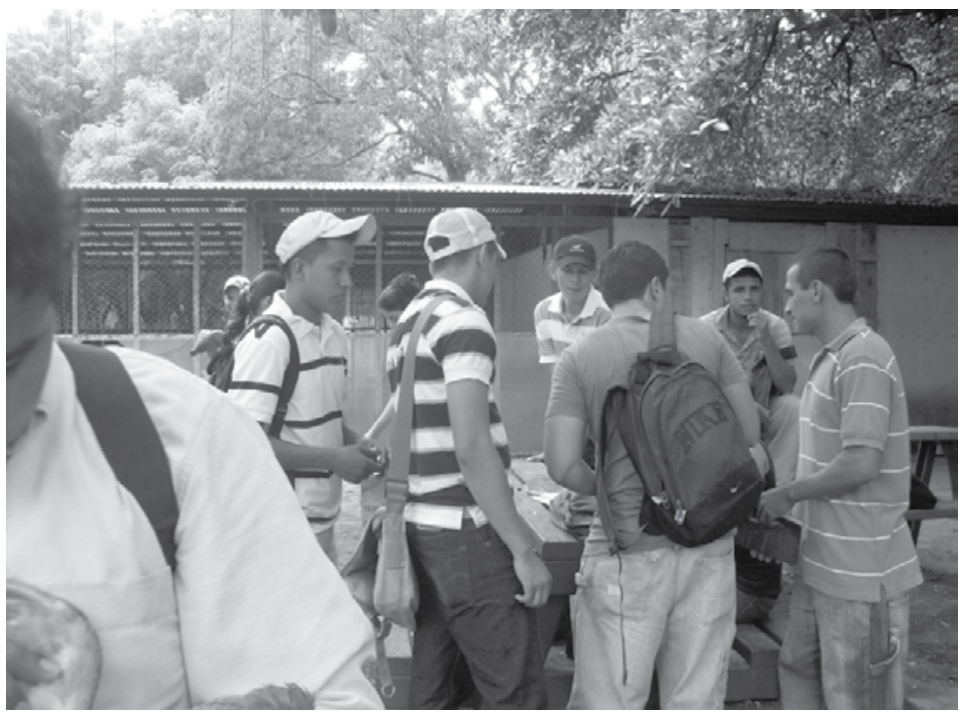

La carrera de medicina Veterinaria y Zootecnia de la Universidad Agraria de la Habana (UNAH) logró la condición de Carrera de Excelencia en el proceso de evaluación externa realizado por Junta Nacional de Acreditación (JAN) en Cuba. Esta certificación jerarquiza la calidad formativa de los profesionales y deja bien posicionado a la Universidad, en la calidad del proceso de formación en las Ciencias Veterinarias y Zootécnicas.

El proceso de acreditación se realizo a partir de una autoevaluación según las variables de calidad establecidas por el SEA-CU, las cuales se relacionan con la Pertinencia e Impacto Social; Profesores y personal auxiliar; Estudiantes; Infraestructura y Currículo.

El proceso implica primero la realización de una autoevaluación y posteriormente la evaluación a cargo de evaluadores externos designados por la JAN. En este caso, la evaluación fue realizada por expertos en Ciencias Medicas de la Habana, Facultad de Ciencia Animal de la UCLV y el CENSA.

Los resultados de la evaluación han puesto de manifiesto fortalezas en las distintas variables, que sustentan los logros integrales de la Carrera en la Institución. Se evidenciaron como aspectos a destacar:
La alta pertinencia e impacto social de la carrera demostrada por el aporte de profesores a la solución de los problemas de la región y los más de 6,000 egresados, entre ellos, varios cientos de extranjeros, la participación de los estudiantes en tareas de la revolución de gran impacto, los aportes significativos a la región con las distintas figuras de postgrado desarrolladas y los resultados de investigación vinculados a líneas priorizadas con una alta satisfacción por parte de los beneficiarios en los proyectos.

El claustro se caracteriza por poseer alto sentido de pertenencia, vocación docente, capacidad de entrega a la búsqueda de soluciones a los problemas que pudieran afectar el proceso docente educativo, elevada experiencia profesional $\mathrm{y}$ reconocimiento de los estudiantes por las cualidades y ejemplaridad como educadores.

Se reconoció que el postgrado de la Carrera (Doctorado, maestrías, especialidades y cursos en general) constituye un sistema consolidado, los cuatro programas de maestría están acreditados, dos de ellos de Excelencia y los resultados de las investigaciones tienen visibilidad con numerosos premios y reconocimientos entre ellos 3 premios de la ACC y dos patentes en los últimos cinco años. 
Los estudiantes muestran dominio de los modos de actuación de la profesión y demuestran compromiso con la Revolución, con su centro de estudios y con su futura profesión, participan activamente en el cumplimiento de las tareas de contenido social y político del territorio. Además, los estudiantes participan en las actividades de investigación vinculadas a los problemas de las unidades de producción o servicios en los cuales realizan su formación.

La Facultad como centro el Centro Rector de la Carrera a nivel nacional realiza sistemáticamente un trabajo de gestión de calidad mediante su instrumentación y perfeccionamiento continuo y un eficiente sistema de trabajo metodológico en los colectivos de la Carrera, disciplinas, años y asignaturas respecto a la organización general docente, objetivos generales, plan de estudio, programa de disciplinas y asignaturas.

Esta acreditación fue posible gracias a la cooperación activa de los docentes, estudiantes y administrativos, así como el apoyo de todas las Instituciones con las que Facultad posee estrechos vínculos de trabajo en el territorio y el País. 